\title{
Medically unexplored stories
}

\section{John Launer}

If you have been reading medical journals over the last couple of years, you will almost certainly have read about "medically unexplained symptoms"-sometimes abbreviated to MUS. The term was first proposed over 20 years ago, but recently it has grown in popularity and in some places it is taking over from similar and overlapping terms such as somatisation, psychosomatic disorders, frequent consulters, "fat file" patients, and so on. Its use has now spread from researchers and clinicians to managers and health service commissioners. If you work in the UK, someone in your speciality or your area will almost certainly be looking into the possibility of identifying patients with MUS and setting up a dedicated service to relieve their distress and save money for the National Health Service.

At first sight, this way of categorising certain symptoms or patients looks highly attractive. Most clinicians, whatever their field, will readily admit to seeing a proportion of patients for whom it is difficult to assign any diagnosis-or where patients will not accept the diagnosis on offer (most doctors appear to estimate this applies to $15-30 \%$ of consultations). Saying that someone has MUS is clearly preferable to calling them a difficult patient or a "heartsink" one. More pertinently, there are now quite a few studies showing that if you separate such people from the bulk of your patients and offer them certain kinds of interventions, they may improve. These interventions include cognitive behaviour therapy $(\mathrm{CBT})^{1}$ and multimodal programmes of stepped care including drug treatment. $^{2}$

The evidence provided by these studies is convincing-at least when judged in terms of their own implicit assumptions. At the same time, I want to argue that the definition of "medically unexplained symptoms" is highly problematical. It may offer no significant advance on the whole range of terms that are now becoming obsolete. It may even lead us down a medical blind alley.

Correspondence to: Dr John Launer, London Department of Postgraduate Medical Education, Stewart House, 32 Russell Square, London WC1B 5DN, UK; jlauner@londondeanery.ac.uk

\section{THE NATURE OF EXPLANATION}

As everyday experience shows, almost all the explanations that doctors offer their patients are only ever partial in their nature. For example, we may tell people that their symptoms are due to thrush, or fibroids, or osteoarthritis of the hip, and these all count as a kind of explanation. But if patients question us as to why they got this particular condition and not another, or why they got it this week and not last month, we are at a loss. Our explanations, in other words, are generally "proximal" rather than "distal" ones: it is usually the patients themselves who decide what the distal ones are, often attributing these to things such as life events or stress at work. With considerable frequency, we also tell people that our diagnosis is far from certain but suggest they try a particular treatment as an experiment. If it works (as it often does) we may be none the wiser as to whether they actually had the condition we suspected, or would have got better anyway.

We can deconstruct the notion of medical explanation even further. To give a classic example: when I was in my late 30s I had an episode of severe chest pain that was diagnosed variously as a myocardial infarction, viral myocarditis and oesophagitis. After I recovered, I lived with this uncertainty for around nearly 20 years until the pain recurred. I then had a battery of further tests that first of all ruled out any possibility of a past ischaemic event, and then "conclusively" confirmed it. I am currently taking my $\beta$-blockers and ACE inhibitors like a well behaved patient, but who knows what future investigative technology may "prove" when I next see a cardiologist? Such explanatory twists and turns, I suggest, are extraordinarily common, especially if we examine people's past medical notes carefully. If we do so, we will also find disease labels that are now totally discredited and obsolete, as well as diagnoses that we still recognise but would no longer apply in the same way. "Medically explained symptoms", in other words, may not be quite what they seem.

\section{SLIPPERY GROUND}

If we move on from the word "explained" to the word "symptoms", we are on even more slippery ground. Patients very rarely bring us symptoms as such. What they bring instead are words and stories, and they point to parts of their bodies that they experience as causing trouble. We as doctors then reframe their narrative accounts and gestures into what we call symptoms. In doing so, we are taking over their experiences and transmuting them into our own familiar forms. But something is always lost in translation. The affect, the meaning, the signification and the entire set of personal contexts that goes with their words and gestures will always remain theirs and can never become ours. Our efforts at interpretation may have a pragmatic purpose, and even a beneficial result, but at a philosophical level we have not actually "explained" anything, let alone everything. We have simply assigned a medical description in place of an individual one.

In some circumstances this barely matters. However, in a large proportion of encounters between doctors and patients it matters a lot. This clearly applies to the cases that are now being labelled as MUS, but it also applies to any interaction where patients feel that they have not been fully understood, or where there has not been enough time to hear them out. The term MUS implies that most medical encounters represent a complete meeting of minds, but there is a lot of evidence from research into the medical consultation to suggest this is unture. In other words, concentrating on MUS focuses our attention on a supposedly aberrant group of patients whom we as doctors find irksome, but it distracts us from noticing what is deficient in our interactional skills more generally.

\section{THE CONTEST OF INTERPRETATIONS}

In a brilliant paper entitled "Explaining medically unexplained symptoms", the Canadian psychiatrist and anthropologist Laurence Kirmayer moves the focus away from MUS to what he calls "the contest of interpretations". ${ }^{3}$ He argues that the narrow focus of the typical clinical encounter does not allow most patients enough time to construct a meaningful narrative about their symptoms. He quotes research that challenges the assumption that patients with unexplained symptoms have "hidden" psychological problems, or are resistant to accepting that their problems may have psychological aspects to them. He describes how physicians respond with physical interventions even when patients neither request nor want this. He speculates that this is due to the way physicians avoid emotional distress, lack strategies to engage with patients' psychosocial problems, and attempt to maintain authority in the face of ambiguous conditions. He suggests that training doctors to address 
psychosocial dimensions and manage their own feelings of incompetence might improve the outcome for patients.

Significantly, Kirmayer does not look for solutions in treatments for the patient. $\mathrm{He}$ argues instead that the responsibility for a change in behaviour rests with us as doctors. "One of the basic tasks of the clinical encounter", he argues, "is the coconstruction of meaning for distress... Only through dialogue, negotiation and cultural exchange can clinicians find explanations that make sense to patients and their families." Perhaps, after all, we should continue to use the abbreviation MUS but acknowledge what it really stands formedically unexplored stories.

Competing interests: None declared.

Provenance and peer review: Commissioned; not externally peer reviewed.
Postgrad Med J 2009:85:503-504.

doi:10.1136/pgmj.2009.087411

\section{REFERENCES}

1. Hatcher S, Arroll B. Assessment and management of medically unexplained symptoms. BMJ 2008;336:1124-8.

2. Smith RC, Lyles JS, Gardiner JC, et al. Primary care clinicians treat patients with medically unexplained symptoms: a randomized controlled trial. J Gen Int Med 2006;21:671-7.

3. Kirmayer L. Explaining medically unexplained symptoms. Can J Psychiatry 2004;49:663-72.

\section{Take advantage of BMJ Journals' remarkable catalogue of titles with Related Collections}

No busy professional has time to browse through all pertinent journals to find relevant articles, but with Related Collections you no longer have to. Follow the "Related Collections" link from any article and use the "Show Collections from other Journals" to expand your search across all BMJ Journals. Or simply follow the "Browse by topic" link on the home page. By setting up your own collections and receiving email alerts every time an article is added to your chosen area, you can build up your own significant body of knowledge. 